\title{
ANALISIS PERILAKU KONSUMEN: POLA PEMBELIAN KOPI SERTA PREFERENSI, KEPUASAN DAN LOYALITAS KONSUMEN KEDAI KOPI
}

\section{CONSUMER BEHAVIOR: PURCHASE PATTERN OF COFFEE, PREFERENCES, SATISFACTION AND LOYALTY OF COFFEE SHOP CONSUMER}

\author{
Elly Rasmikayati ${ }^{*}$, Alvi Nurin Deaniera ${ }^{1}$, Dika Supyandi ${ }^{1}$, Yayat Sukayat ${ }^{1}$, \\ Bobby Rachmat Saefudin ${ }^{2}$
}

${ }^{1}$ Fakultas Pertanian, Universitas Padjadjaran, Jl. Ry Bandung-Sumedang KM.21 Jatinangor, 45363

${ }^{2}$ Fakultas Pertanian, Ma'soem University, Jl. Raya Cipacing No. 22 Jatinangor, 45363

*E-mail: e.rasmikayati@unpad.ac.id

(Diterima 11-07-2020; Diterima 25-07-2020)

\begin{abstract}
ABSTRAK
Pengusaha kedai kopi tidak saja harus mampu menjual produk dan jasanya, tetapi juga harus mempunyai kemampuan untuk mengerti dan memahami selera konsumen. Penelitian ini bertujuan untuk mengkaji perilaku konsumen kedai kopi dari aspek pola pembelian kopi, preferensi, kepuasan dan loyalitas konsumen. Penelitian dilakukan di 2 kedai kopi yaitu Jigana Coffee Shop dan Kedai Kopi Inspirasi yang berlokasi di Kecamatan Cibinong, Kabupaten Bogor, Jawa Barat. Penelitian ini menggunakan desain penelitian kuantitatif yang dilakukan dengan metode survey pada 27 konsumen Jigana Coffee Shop dan 45 konsumen Kedai Kopi Inspirasi yang didapatkan melalui teknik sampling systematic melalui perhitungan rumus Cochran. Data dianalisis menggunakan tabel distribusi frekuensi. Hasil penelitian menunjukkan bahwa pola pembelian kopi oleh konsumen di Jigana Coffee Shop dan Kedai Kopi Inspirasi kebanyakan dengan alasan sekadar ingin mencoba dan ingin mendapatkan suasana yang nyaman dengan minum kopi di kedai kopi dan bercengkrama bersama teman atau pasangan pada sekitar jam 17.00 hingga 21.00. Adanya potongan harga dan promosi "buy one get one" sangat mempengaruhi minat konsumen untuk berkunjung ke kedai kopi. Sementara dari segi preferensi konsumen, jenis minuman yang paling disukai adalah Espresso based dan Manual Brew. Sedangkan untuk jenis minuman yang paling disukai konsumen adalah kentang goreng dan roti bakar. Kemudian mengenai kepuasan dan loyalitas, sebagian besar konsumen merasa puas setelah melakukan kunjungan ke kedai kopi dan berminat untuk melakukan kunjungan ulang.
\end{abstract}

Kata kunci: Perilaku petani, pola pembelian, preferensi, kepuasan, loyalitas, konsumen, kedai kopi

\section{ABSTRACT}

Coffee shop entrepreneurs must not only be able to sell their products and services, but also must have the ability to understand consumer tastes. This study aims to examine the behavior of coffee shop consumers from aspects of coffee buying patterns, preferences, satisfaction and customer loyalty. The study was conducted in 2 coffee shops namely Jigana Coffee Shop and Kedai Kopi Inspirasi located in Cibinong District, Bogor Regency, West Java. This study uses a quantitative research design conducted by survey methods on 27 consumers of Jigana Coffee Shop and 45 consumers of Kedai Kopi Inspirasi obtained through systematic sampling techniques through the calculation of the Cochran formula. Data analyzed using frequency distribution tables. The results showed that the pattern of coffee purchases by consumers in Jigana Coffee Shop and Coffee Shop Inspiration mostly with the reason simply wanted to try and want to get a comfortable atmosphere by drinking coffee in a coffee shop and chatting with friends or spouse around 17:00 to 21:00. Discounts and "buy one get one" promotions greatly affect consumer interest in visiting coffee shops. While in terms of consumer preferences, the most preferred types of drinks are Espresso based and Manual Brew. As for the types of drinks the most preferred by consumers are french 
fries and toast. Then regarding satisfaction and loyalty, most consumers were satisfied after a visit to the coffee shop and were interested in making a repeat visit.

Keywords: Farmer's behavior, purchasing patterns, preferences, satisfaction, loyalty, consumers, coffee shops

\section{PENDAHULUAN}

Salah satu sektor yang menyumbang kontribusi terbesar terhadap peningkatan PDRB Kabupaten Bogor adalah sektor perdagangan, hotel, dan restoran. Salah satu penyebab peningkatan aktivitas bisnis kuliner di Kabupaten Bogor yaitu karena adanya perubahan lifestyle dan pola perilaku masyarakat Indonesia yang semakin konsumtif. Kedai kopi adalah salah satu industri kuliner yang saat ini semakin populer dan terkenal di wilayah Kabupaten Bogor.

Kedai kopi atau coffee shop adalah sebuah tempat yang menyediakan minuman seperti minuman coffee, non coffee dan makanan kecil. Saat ini, kedai kopi juga merupakan salah satu jenis restoran yang sedang berkembang cukup pesat di Kecamatan Cibinong. Hal tersebut didukung dengan munculnya beberapa franchise kedai kopi yang ada di Cibinong, diantaranya Starbucks, Janji Jiwa, Kulo, dan kedai kopi franchise lainnya. Tidak menutup kemungkinan, ada juga beberapa pelaku usaha bisnis yang memilih untuk membuka kedai kopi dengan memulai usahanya menggunakan brand sendiri. Jigana Coffee Shop dan Kedai Kopi Inspirasi merupakan kedai kopi yang ada di wilayah Cibinong dan memulai usahanya dengan menggunakan brand sendiri.

Pengusaha kedai kopi tidak saja harus mampu menjual produk dan jasanya, tetapi juga harus mempunyai kemampuan untuk mengerti dan memahami selera konsumen karena konsumen merupakan salah satu penentu kelangsungan hidup suatu usaha, tanpa konsumen, perusahaan tidak punya tujuan untuk memasarkan barang atau jasanya.

Ada berbagai proses yang terlibat dalam perilaku konsumen yang dapat memengaruhi individu dalam dirinya, antara lain: (a) proses pengambilan keputusan, (b) kebiasaan berbelanja, (c) perilaku pembelian, (d) merek yang dibeli, atau (e) pengecer yang dituju (Ramya \& Ali, 2016). Perilaku seseorang yang selalu berubah dan juga bergerak sepanjang waktu ini mengindikasikan bahwa perilaku konsumen ini memiliki sifat yang dinamis (Setiadi, 2013). Keputusan pembelian merupakan hasil 
dari masing-masing dari semua faktor yang ada. Penting sekali untuk memeriksa sikap dan perilaku pembelian konsumen karena mungkin ada faktorfaktor seperti harga, ketersediaan produk, dan pengaruh sosial yang dapat menyebabkan perbedaan antara sikap konsumen, niat pembelian dan perilaku pembelian aktual (Singh \& Verma, 2017).

Oleh karena itu, penting kiranya pihak kedai kopi melakukan upaya mendengar suara pelanggan atau yang disebut dengan "listening to the voice of customer". Dengan pemahaman terhadap suara konsumen maka perilaku konsumen dapat dipetakan. Setelah itu, perumusan tingkat kepuasan dan loyalitas konsumen pun akan mudah dijabarkan dan kedai kopi dapat memperbaiki kekurangan dan meningkatkan kinerja untuk kemajuan, kemampuan untuk bersaing sehingga diharapkan dapat meningkatkan penjualan seiring bertambahnya konsumen.

Berdasarkan uraian-uraian di atas, penelitian ini bertujuan untuk mengkaji perilaku konsumen kedai kopi dari aspek pola pembelian kopi, preferensi, kepuasan dan loyalitas konsumen.

\section{METODE PENELITIAN}

Tempat dan Waktu Penelitian

Objek penelitian ini adalah pola pembelian kopi, preferensi, kepuasan dan loyalitas konsumen setelah berkunjung ke kedai kopi. Penelitian dilakukan pada 2 kedai kopi, yaitu Jigana Coffee Shop dan Kedai Kopi Inspirasi yang berlokasi di Kecamatan Cibinong, Kabupaten Bogor, Jawa Barat. Dua kedai kopi tersebut dipilih dengan pertimbangan adanya perbedaan kestrategisan lokasi. Jigana Coffee Shop lokasi kedainya strategis, sedangkan Kedai Kopi Inspirasi lokasinya relatif tidak begitu strategis.

\section{Desain Penelitian}

Penelitian ini menggunakan desain penelitian kuantitatif yang dilakukan dengan metode survey pada konsumen Jigana Coffee Shop dan Kedai Kopi Inspirasi.

\section{Variabel Penelitian}

1) Perilaku konsumen

a) Alasan berkunjung, yaitu alasan konsumen berkunjung ke kedai kopi.

b) Media yang mempengaruhi, yaitu media yang mempengaruhi keputusan berkunjung konsumen ke kedai kopi. 
c) Bentuk promosi, yaitu suatu bentuk promosi yang menarik bagi konsumen.

d) Manfaat yang dicari, yaitu manfaat yang dicari oleh konsumen pada waktu berkunjung ke kedai kopi.

e) Frekuensi pembelian, yaitu rentang waktu konsumen dalam membeli produk kopi dengan volume tertentu dan kontinu dalam periode tertentu.

f) Orang yang menemani berkunjung, yaitu orang yang menemani konsumen berkunjung ke kedai kopi.

g) Hari berkunjung, yaitu hari berkunjung konsumen ke kedai kopi.

h) Jam berkunjung, yaitu jam berkunjung konsumen ke kedai kopi.

i) Biaya yang dikeluarkan, yaitu biaya yang dikeluarkan oleh konsumen saat berkunjung ke kedai kopi.

2) Preferensi konsumen kopi terhadap varian menu kedai kopi.

a) Menu kopi yang disukai, yaitu menu kopi yang paling disuka oleh konsumen di kedai kopi.

b) Menu kopi yang tidak disukai, yaitu menu kopi yang paling tidak disukai oleh konsumen di kedai kopi.

c) Menu makanan pelengkap yang paling disukai, yaitu menu makanan yang paling disukai oleh konsumen di kedai kopi.

3) Kepuasan konsumen setelah berkunjung ke kedai kopi

4) Loyalitas konsumen setelah berkunjung ke kedai kopi dinilai berdasarkan minat konsumen untuk melakukan kunjungan ulang ke kedai kopi.

\section{Teknik Penarikan Sampel}

Teknik sampling yang digunakan adalah systematic sampling method atau teknik sampling sistematis yang merupakan teknik penentuan sampel yang dilakukan berdasarkan nomor urut anggota populasi (Sugiyono, 2018). Penentuan ukuran sampel penelitian dilakukan berdasarkan perhitungan rumus Cochran sedemikian rupa sehingga didapatkan ukuran sampel sebesar 27 responden untuk konsumen Jigana Coffee Shop dan 45 responden untuk konsumen Kedai Kopi Inspirasi.

\section{Rancangan Analisis Data}

Rancangan analisis data dilakukan menggunakan statistika deskriptif berupa 
tabel distribusi frekuensi. Alat statistik ini merupakan statisik yang digunakan untuk menganalisis data dengan mendeskripsikan atau menggambarkan data yang terkumpul secara jelas (Sugiyono, 2018). Peneliti dapat menggunakan statistik deskriptif sebagai alat analisis penelitiannya apabila hanya ingin mendeskripsikan data sampel, tidak bermaksud untuk memberikan kesimpulan yang berlaku untuk populasi.

\section{HASIL DAN PEMBAHASAN}

\section{Pola Pembelian Kopi}

Keputusan kunjungan oleh seseorang ke kedai kopi diawali pada saat seseorang tersebut menyadari akan kebutuhannya yang harus dipenuhi oleh dirinya (Afriyanti dan Rasmikayati, 2018). Dalam penelitian ini, terdapat perbedaan mengenai alasan utama responden mengunjungi Jigana Coffee Shop dan Kedai Kopi Inspirasi. Untuk mengetahui sebaran responden menurut alasan utama berkunjung dari Jigana Coffee Shop dan Kedai Kopi Inspirasi tersaji dalam Tabel 1.

Jika dibandingkan antara Jigana Coffee Shop dan Kedai Kopi Inspirasi, alasan sekedar ingin mencoba lebih banyak dipilih responden yang berkunjung ke Jigana Coffee Shop.
Alasan lainnya responden berkunjung ke Jigana Coffee Shop diantaranya yaitu sebagai tempat nongkrong, pertemuan bisnis, kencan, karena kebetulan lewat, serta ada pula yang memiliki alasan karena teman dari pemilik kedai kopi. Jigana Coffee Shop ini memang memiliki lokasi yang strategis, dimana letaknya ada di posisi kiri pada Jalan Raya Alternatif Cibinong-Bogor-Depok, Ruko Perumahan Cibinong Griya Asri. Sehingga, tidak heran apabila banyak pengendara motor atau mobil yang berhenti untuk sekedar beristirahat sambil menikmati kopi di kedai ini.

Tabel 1. Alasan Konsumen Berkunjung ke Kedai Kopi

\begin{tabular}{lcccc}
\hline \multirow{2}{*}{$\begin{array}{c}\text { Alasan } \\
\text { Berkunjung }\end{array}$} & \multicolumn{2}{c}{$\begin{array}{c}\text { Jigana Coffee } \\
\text { Shop }\end{array}$} & \multicolumn{2}{c}{$\begin{array}{c}\text { Kedai Kopi } \\
\text { Inspirasi }\end{array}$} \\
\cline { 2 - 5 } & $\mathrm{n}$ & $\%$ & $\mathrm{n}$ & $\%$ \\
\hline$-\begin{array}{l}\text { Rasa } \\
\text { lapar/haus }\end{array}$ & 5 & 19 & - & - \\
$-\begin{array}{l}\text { Sekadar } \\
\text { ingin coba }\end{array}$ & 8 & 29 & 12 & 27 \\
$-\begin{array}{l}\text { Harga yang } \\
\text { terjangkau }\end{array}$ & 5 & 19 & 5 & 11 \\
$-\begin{array}{l}\text { Suasana } \\
\text { yang } \\
\text { nyaman }\end{array}$ & 2 & 7 & 20 & 44 \\
$-\begin{array}{l}\text { Menu yang } \\
\text { beragam }\end{array}$ & - & - & 1 & 2 \\
$-\begin{array}{l}\text { Rasa yang } \\
\text { khas }\end{array}$ & 4 & 15 & - & - \\
- Lokasi & 1 & 4 & 4 & 9 \\
- Lainnya & 2 & 7 & 3 & 7 \\
\hline$\quad$ Jumlah & 27 & 100 & 45 & 100 \\
\hline Sumber: Analisis data primer (2020) &
\end{tabular}

Sedangkan, mayoritas responden Kedai Kopi Inspirasi menyatakan bahwa alasan utama mereka berkunjung adalah 
cenderung pada menikmati suasana yang nyaman. Hal ini disebabkan Kedai Kopi Inspirasi ini memang memiliki suasana yang nyaman dan desain tempat yang menarik dan unik, sehingga tempat ini sering dijadikan tempat untuk berkumpul, pertemuan bisnis, dan kencan oleh konsumennya. Barista yang friendly dan juga fasilitas tambahan seperti musik, dan lainnya juga membuat Kedai Kopi Inspirasi nyaman untuk dikunjungi.

Hasil penelitian ini juga sesuai dengan hasil penelitian Saefudin dkk. (2020) yang menyatakan bahwa mayoritas motivasi kunjungan konsumen adalah tempat yang nyaman. Mayoriyas konsumen Kedai Kopi Inspirasi ini adalah yang berusia 20-30 tahun dengan status pekerjaan sebagai mahasiswa/i atau pelajar, sehingga menyebabkan konsumen memilih suatu kedai kopi yang memiliki tempat yang nyaman. Konsumen dalam usia tersebut cenderung memiliki aktivitas yang banyak di luar rumah dan sedikit waktu luang di dalam rumah, sehingga mereka mencari tempat yang nyaman dan tidak memungkinkan didapat di rumah.

Setelah kebutuhan dikenali, konsumen akan mencari informasi untuk mempertimbangkan tindakan pembelian yang juga akan memberikan kepuasan
Afriyanti dan Rasmikayati (2018). Pencarian informasi mengenai produk ini juga bisa dilakukan secara internal, seperti pengetahuan dan ingatan maupun secara eksternal, seperti informasi dari media massa, lingkungan teman dan keluarga. Untuk mengetahui sebaran responden berdasarkan media yang mempengaruhi keputusan untuk melakukan kunjungan ke Jigana Coffee Shop dan Kedai Kopi Inspirasi tersaji pada Tabel 2 .

Tabel 2. Media yang Mempengaruhi Keputusan Berkunjung ke Kedai Kopi

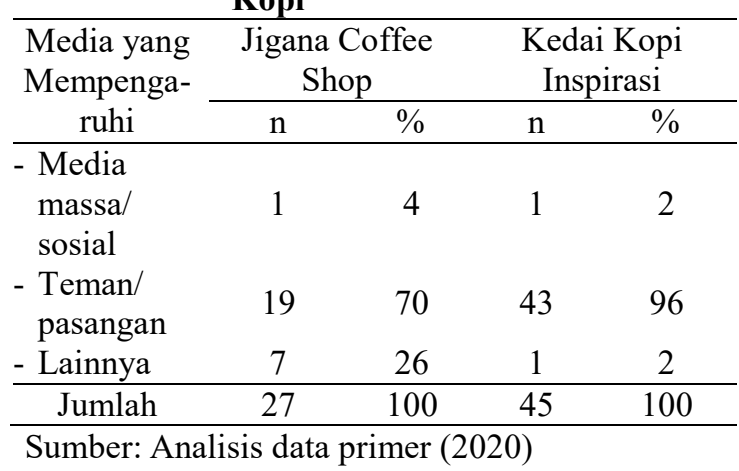

Berdasarkan Tabel 2, dapat diketahui bahwa teman/pasangan merupakan sumber informasi yang paling mempengaruhi responden Jigana Coffee Shop dan Kedai Kopi Inspirasi ini dalam melakukan kunjungan ke kedai kopi pilihan mereka dengan persentase 70 persen pada Jigana Coffee Shop dan 96 persen pada Kedai Kopi Inspirasi. Hal ini dikarenakan orang terdekat yang paling sering berkomunikasi dengan responden 
adalah teman atau pasangan. Informasi dari teman tersebut merupakan hasil pengalaman nyata yang dapat direkomendasikan kepada orang lain, sehingga mempengaruhi keputusan responden melakukan kunjungan ke kedai kopi pilihannya (Rasmikayati dkk., 2017).

Berdasarkan informasi tersebut, bentuk promosi word of mouth juga merupakan salah satu bentuk promosi yang cukup efektif mengingat teman memberikan pengaruh yang cukup besar dalam mendorong konsumen untuk melakukan pembelian di kedua kedai kopi. Hasil penelitian ini juga sesuai dengan hasil penelitian Afriyanti dan Rasmikayati (2018) yang menyatakan bahwa pihak yang mempengaruhi keputusan berkunjung konsumen ialah teman. Jika dibandingkan antara Jigana Coffee Shop dan Kedai Kopi Inspirasi, media yang mempengaruhi responden untuk berkunjung ke Jigana Coffee Shop selain teman/pasangan yaitu keluarga.

Kemudian, salah satu faktor yang mempengaruhi konsumen dalam berkunjung ke kedai kopi pilihan mereka adalah promosi (Afriyanti dan Rasmikayati, 2018). Dengan adanya promosi atau penawaran khusus, maka akan membuat ketertarikan konsumen untuk berkunjung ke kedai kopi tersebut. Untuk mengetahui sebaran responden berdasarkan bentuk promosi yang menarik bagi konsumen Jigana Coffee Shop dan Kedai Kopi Inspirasi tersaji pada Tabel 3 .

Tabel 3. Bentuk Promosi yang Menarik Bagi Konsumen

\begin{tabular}{|c|c|c|c|c|}
\hline \multirow{2}{*}{$\begin{array}{c}\text { Bentuk } \\
\text { Promosi }\end{array}$} & \multicolumn{2}{|c|}{$\begin{array}{c}\text { Jigana Coffee } \\
\text { Shop }\end{array}$} & \multicolumn{2}{|c|}{$\begin{array}{l}\text { Kedai Kopi } \\
\text { Inspirasi }\end{array}$} \\
\hline & $\mathrm{n}$ & $\%$ & $\mathrm{n}$ & $\%$ \\
\hline $\begin{array}{l}\text { - Potongan } \\
\text { harga }\end{array}$ & 8 & 30 & 12 & 27 \\
\hline $\begin{array}{l}\text { - Buy one } \\
\text { get one }\end{array}$ & 8 & 30 & 15 & 34 \\
\hline - Member & 2 & 7 & 2 & 4 \\
\hline - Kupon & - & - & 1 & 2 \\
\hline $\begin{array}{r}\text { - Cashback } \\
\text { gopay/ovo }\end{array}$ & 6 & 22 & 13 & 29 \\
\hline - Lainnya & 3 & 11 & 2 & 4 \\
\hline Jumlah & 27 & 100 & 45 & 100 \\
\hline
\end{tabular}

Sumber: Analisis data primer (2020)

Berdasarkan Tabel 3, responden Jigana Coffee Shop dan Kedai Kopi Inspirasi lebih banyak memilih buy one get one sebagai bentuk promosi yang paling diharapkan. Hal ini dikarenakan responden yang datang dapat membagi harga berdua dengan teman lainnya, sehingga diharapkan agar dapat mengurangi biaya yang mereka keluarkan saat berkunjung ke kedai kopi. Namun, apabila dilihat dari hasil data Tabel 3, persentase hasil potongan harga dan buy one get one pada Jigana Coffee Shop besarnya sama, yaitu 30 persen. Hal tersebut juga menandakan bahwa potongan harga juga merupakan salah 
satu bentuk promosi yang paling diharapkan oleh konsumen Jigana Coffee Shop.

Tahap selanjutnya yaitu tahap dimana konsumen menetapkan kriteriakriteria tertentu yang sesuai dengan keinginannya. Kriteria yang mendorong konsumen berkunjung ke kedai kopi adalah manfaat yang dicari. Untuk mengetahui sebaran responden berdasarkan manfaat yang dicari pada waktu berkunjung ke Jigana Coffee Shop dan Kedai Kopi Inspirasi tersaji pada Tabel 4.

Tabel 4. Manfaat yang Dicari pada Waktu Berkunjung ke Kedai Kopi

\begin{tabular}{|c|c|c|c|c|}
\hline \multirow{2}{*}{$\begin{array}{c}\text { Manfaat } \\
\text { yang Dicari }\end{array}$} & \multicolumn{2}{|c|}{$\begin{array}{c}\text { Jigana Coffee } \\
\text { Shop }\end{array}$} & \multicolumn{2}{|c|}{$\begin{array}{l}\text { Kedai Kopi } \\
\text { Inspirasi }\end{array}$} \\
\hline & $\mathrm{n}$ & $\%$ & $\mathrm{n}$ & $\%$ \\
\hline $\begin{array}{l}\text { - Rasa yang } \\
\text { enak/ } \\
\text { nikmat }\end{array}$ & 19 & 70 & 11 & 25 \\
\hline $\begin{array}{l}\text { - Menikmati } \\
\text { suasana } \\
\text { yang } \\
\text { ditawarkan }\end{array}$ & 4 & 15 & 28 & 62 \\
\hline $\begin{array}{l}\text { - Gaya } \\
\text { hidup/ } \\
\text { trend }\end{array}$ & 1 & 4 & 5 & 11 \\
\hline - Lainnya & 3 & 11 & 1 & 2 \\
\hline Jumlah & 27 & 100 & 45 & 100 \\
\hline
\end{tabular}

Sumber: Analisis data primer (2020)

Berdasarkan Tabel 4, dapat diketahui bahwa responden Jigana Coffee Shop berkunjung ke kedai kopi tersebut untuk mencari rasa yang enak/nikmat. Sebagai minuman yang memiliki citarasa khas yang tidak dimiliki oleh bahan minuman lainnya, kopi termasuk menjadi salah satu minuman favorit yang digemari berbagai kalangan dalam segala suasana.

Sedangkan, responden Kedai Kopi Inspirasi sebagian besar berkunjung ke kedai kopi tersebut untuk menikmati suasana yang ditawarkan. Padatnya rutinitas yang dijalani juga menjadi salah satu faktor responden mencari tempat yang nyaman untuk berkumpul dan bersantai bersama teman, pasangan, maupun keluarga. Hasil tersebut juga menunjukkan bahwa suasana tempat yang ditawarkan Kedai Kopi Inspirasi ini menandingi cita rasa kopi sebagai pertimbangan sebagian besar konsumen dalam berkunjung. Hasil penelitian ini memiliki persamaan dengan hasil penelitian Afriyanti dan Rasmikayati (2018) yang menyatakan bahwa pertimbangan kunjungan mayoritas konsumen ialah suasana tempat.

Setelah itu, tahap selanjutnya yaitu dapat dilihat dari cara frekuensi kunjungan, hari melakukan kunjungan, waktu melakukan kunjungan, dan biaya yang dikeluarkan. Untuk variabel menu yang disukai dan tidak disukai diadopsi oleh penulis dengan pertimbangan preferensi konsumen terhadap menu yang ada yang mempengaruhi keputusan pembelian konsumen. Untuk mengetahui 
sebaran responden berdasarkan frekuensi kedatangan ke Jigana Coffee Shop dan Kedai Kopi Inspirasi tersaji pada Tabel 5.

Tabel 5. Frekuensi Kedatangan ke Kedai Kopi

\begin{tabular}{ccccc}
\hline \multirow{2}{*}{$\begin{array}{c}\text { Frekuensi } \\
\text { Kedatangan }\end{array}$} & \multicolumn{2}{c}{$\begin{array}{c}\text { Jigana Coffee } \\
\text { Shop }\end{array}$} & \multicolumn{2}{c}{$\begin{array}{c}\text { Kedai Kopi } \\
\text { Inspirasi }\end{array}$} \\
\cline { 2 - 5 } & $\mathrm{n}$ & $\%$ & $\mathrm{n}$ & $\%$ \\
\hline $\begin{array}{c}-<3 \mathrm{kali} / \\
\text { minggu }\end{array}$ & 24 & 89 & 41 & 91 \\
$-\begin{array}{c}->3 \mathrm{kali} / \\
\text { minggu }\end{array}$ & 3 & 11 & 4 & 9 \\
\hline Jumlah & 27 & 100 & 45 & 100 \\
\hline Sumber: Analisis data primer $(2020)$ &
\end{tabular}

Berdasarkan Tabel 5, dapat disimpulkan bahwa responden dari Jigana Coffee Shop dan Kedai Kopi Inspirasi melakukan kunjungan ke kedai kopi pilihannya rata-rata kurang dari tiga kali per minggu. Berdasarkan pendapat dari beberapa konsumen, hal ini karena mayoritas dari mereka memiliki kegiatan lain. Selain itu, juga mereka memiliki budget yang terbatas sehingga tidak bisa terlalu sering berkunjung ke kedai kopi. Namun, rata-rata kunjungan tersebut menunjukkan bahwa sebagian besar responden memiliki loyalitas yang cukup tinggi terhadap kedai kopi pilihan mereka. Hal tersebut dikarenakan mereka secara rutin melakukan kunjungan per minggunya.

Jika dibandingkan antara Jigana Coffee Shop dan Kedai Kopi Inspirasi, tidak terdapat perbedaan yang terlalu jauh pada persentase frekuensi kedatangan

konsumen. Hal tersebut karena kopi memang merupakan minuman selingan, sehingga kunjungan yang dilakukan konsumen terbatas.

Selanjutnya, orang yang menemani konsumen berkunjung sebagian besar responden Jigana Coffee Shop dan Kedai Kopi Inspirasi berkunjung ke kedai kopi pilihannya bersama teman atau pasangan mereka. Bagi mereka, hal tersebut dinilai cocok untuk dijadikan tempat bersantai dan nongkrong. Hasil penelitian ini sesuai dengan penelitian Damanik (2008) yang menyatakan bahwa pada umumnya, kedai kopi merupakan pilihan tempat yang cukup nyaman bagi responden untuk berkumpul dan bersantai bersama teman atau pasangan mereka ataupun tempat untuk melepas kepenatan dari rutinitas sehari-hari. Sebaran responden berdasarkan orang yang menemani berkunjung ke Jigana Coffee Shop dan Kedai Kopi Inspirasi tersaji pada Tabel 6.

Tabel 6. Orang yang Menemani Berkunjung ke Kedai Kopi

\begin{tabular}{lcccc}
\hline \multirow{2}{*}{$\begin{array}{c}\text { Orang yang } \\
\text { Menemani }\end{array}$} & \multicolumn{2}{c}{$\begin{array}{c}\text { Jigana Coffee } \\
\text { Shop }\end{array}$} & \multicolumn{2}{c}{$\begin{array}{c}\text { Kedai Kopi } \\
\text { Inspirasi }\end{array}$} \\
\cline { 2 - 5 } Berkunjung & $\mathrm{n}$ & $\%$ & $\mathrm{n}$ & $\%$ \\
\hline - Sendiri & 4 & 15 & - & - \\
- Teman/ & 13 & 48 & 45 & 100 \\
Pasangan & 10 & 37 & - & - \\
- Keluarga & 10 & 100 & 45 & 100 \\
\hline \multicolumn{1}{c}{ Jumlah } & 27 & \multicolumn{2}{c}{ - } &
\end{tabular}


Jika dibandingkan antara Jigana Coffee Shop dan Kedai Kopi Inspirasi, responden yang ditemani teman/pasangan di Jigana Coffee Shop lebih kecil persentasenya. Hal ini dikarenakan pengunjung Jigana Coffee Shop yang memilih melakukan kunjungan ke kedai kopi pilihan mereka tidak selalu bersama teman/pasangan, melainkan sendiri dan bersama keluarga.

Kemudian, pemilihan kedai kopi yang akan dikunjungi didasarkan pada faktor ketersediaan akan waktu yang dimiliki oleh konsumen itu sendiri. Berdasarkan survey, diketahui sebagian besar responden Jigana Coffee Shop dan Kedai Kopi Inspirasi memilih melakukan kunjungan ke kedai kopi pilihan mereka pada hari libur. Hasil penelitian ini sesuai dengan penelitian Damanik (2008) yang menyatakan bahwa besarnya jumlah responden kedai kopi yang memilih hari libur dikarenakan waktu yang mereka miliki lebih banyak dibanding jika mereka melakukan kunjungan di hari kerja. Sebaran responden berdasarkan hari berkunjung ke Jigana Coffee Shop dan Kedai Kopi Inspirasi tersaji pada Tabel 7.

Jika dibandingkan antara Jigana Coffee Shop dan Kedai Kopi Inspirasi, responden yang melakukan kunjungan pada hari libur di Kedai Kopi Inspirasi lebih kecil persentasenya. Hal ini dikarenakan pengunjung Kedai Kopi Inspirasi tidak selalu melakukan kunjungan pada hari libur, tetapi juga pada hari kerja dengan tujuan untuk mengisi waktu untuk bersantai dan mencari hiburan setelah berkegiatan sekolah ataupun bekerja. Beberapa dari mereka juga melakukan kunjungan dalam rangka memenuhi hobi mereka untuk mencicipi kopi.

Tabel 7. Hari Berkunjung ke Kedai Kopi

\begin{tabular}{ccccc}
\hline \multirow{2}{*}{$\begin{array}{c}\text { Hari } \\
\text { Berkunjung }\end{array}$} & \multicolumn{2}{c}{$\begin{array}{c}\text { Jigana Coffee } \\
\text { Shop }\end{array}$} & \multicolumn{2}{c}{$\begin{array}{c}\text { Kedai Kopi } \\
\text { Inspirasi }\end{array}$} \\
\cline { 2 - 5 } & $\mathrm{n}$ & $\%$ & $\mathrm{n}$ & $\%$ \\
\hline - Hari kerja & 7 & 26 & 13 & 29 \\
- Hari libur & 20 & 74 & 32 & 71 \\
\hline Jumlah & 27 & 100 & 45 & 100 \\
\hline
\end{tabular}

Sumber: Analisis data primer (2020)

Selanjutnya, sebagian besar responden dari Jigana Coffee Shop dan Kedai Kopi Inspirasi memilih berkunjung antara pukul 17.01-22.00 WIB. Hal ini sesuai dengan hasil dari penelitian Afriyanti dan Rasmikayati (2018) bahwa sebagian besar konsumen kopi berkunjung ke kedai kopi antara pukul 17.01-22.00 WIB. Selain itu, sore hari juga dianggap menjadi waktu yang tepat untuk bersantai sambil melepas penat ataupun hanya untuk sekedar bertemu dengan teman atau pasangan. Sebaran responden berdasarkan waktu berkunjung 
ke Jigana Coffee Shop dan Kedai Kopi Inspirasi tersaji pada Tabel 8 .

Tabel 8. Jam Berkunjung ke Kedai Kopi

\begin{tabular}{|c|c|c|c|c|}
\hline \multirow{2}{*}{$\begin{array}{c}\text { Jam } \\
\text { Berkunjung }\end{array}$} & \multicolumn{2}{|c|}{$\begin{array}{c}\text { Jigana Coffee } \\
\text { Shop } \\
\end{array}$} & \multicolumn{2}{|c|}{$\begin{array}{c}\text { Kedai Kopi } \\
\text { Inspirasi }\end{array}$} \\
\hline & $\mathrm{n}$ & $\%$ & $\mathrm{n}$ & $\%$ \\
\hline $\begin{array}{r}-13.01- \\
17.00 \mathrm{WIB}\end{array}$ & 5 & 19 & 1 & 2 \\
\hline $\begin{array}{l}-17.01- \\
21.00 \mathrm{WIB}\end{array}$ & 22 & 81 & 32 & 71 \\
\hline $\begin{array}{l}->21.00 \\
\text { WIB }\end{array}$ & - & - & 12 & 27 \\
\hline Jumlah & 27 & 100 & 45 & 100 \\
\hline
\end{tabular}

Sumber: Analisis data primer (2020)

Jika dibandingkan antara Jigana Coffee Shop dan Kedai Kopi Inspirasi, persentase responden yang melakukan kunjungan pada pukul 17.01-21.00 WIB di Kedai Kopi Inspirasi itu lebih kecil dibandingkan Jigana Coffee Shop, yaitu 71 persen. Hal ini dikarenakan pengunjung Kedai Kopi Inspirasi tidak hanya melakukan kunjungan pada pukul 17.00-21.00 WIB saja, tetapi juga di atas pukul 21.00 WIB.

Kemudian, rata-rata jumlah biaya yang dikeluarkan oleh sebagian besar responden Jigana Coffee Shop pada waktu berkunjung ke kedai kopi pilihan mereka adalah antara Rp 50.000 - Rp 100.000. Hal ini dikarenakan pengunjung Jigana Coffee Shop mayoritas berpendidikan akhir sarjana/S1, dimana pada umumnya sebagian dari mereka sudah memiliki pendapatan per bulan secara stabil. Berbeda halnya dengan
Kedai Kopi Inspirasi, jumlah biaya yang dikeluarkan sebagian besar dari responden kedai kopi tersebut adalah kurang dari Rp 50.000. Hal ini berkaitan dengan tingkat pendapatan dan pekerjaan mereka yang sebagian besar adalah pelajar/mahasiswa/i. Sebaran responden berdasarkan biaya yang dikeluarkan saat berkunjung ke Jigana Coffee Shop dan Kedai Kopi Inspirasi tersaji pada Tabel 9.

Tabel 9. Biaya yang Dikeluarkan Saat Berkunjung ke Kedai Kopi

\begin{tabular}{lcccc}
\hline \multirow{2}{*}{$\begin{array}{c}\text { Biaya yang } \\
\text { Dikeluarkan }\end{array}$} & \multicolumn{2}{c}{$\begin{array}{c}\text { Jigana Coffee } \\
\text { Shop }\end{array}$} & \multicolumn{2}{c}{$\begin{array}{c}\text { Kedai Kopi } \\
\text { Inspirasi }\end{array}$} \\
\cline { 2 - 5 } & $\mathrm{n}$ & $\%$ & $\mathrm{n}$ & $\%$ \\
\hline$-13.01-$ & 5 & 19 & 1 & 2 \\
$\begin{array}{l}17.00 \text { WIB } \\
-17.01-\end{array}$ & 22 & 81 & 32 & 71 \\
$\begin{array}{l}21.00 \text { WIB } \\
->21.00\end{array}$ & - & - & 12 & 27 \\
WIB & - & & & \\
\hline \multicolumn{1}{l}{ Jumlah } & 27 & 100 & 45 & 100 \\
\hline
\end{tabular}

Sumber: Analisis data primer (2020)

\section{Preferensi Konsumen Kopi terhadap Varian Menu Kedai Kopi}

Jenis kopi yang ada di kedai kopi biasanya dapat dilihat dari jenis minuman yang ada dan dibuat oleh kedai kopi itu sendiri. Namun, pada dasarnya terdapat dua jenis minuman kopi yang ada, yaitu espresso-based coffee dan manual brew coffee. Jika dilihat dari hasil penelitian, sebagian besar dari responden Jigana Coffee Shop ini lebih menyukai espresso based coffee. Hal tersebut karena menu espresso yang ada sekarang tidak selalu 
dengan karakteristik panas, berwarna hitam, dan pahit saja tetapi juga cenderung manis, dingin dan tidak hitam karena menggunakan campuran susu, creamer, es, caramel, gula aren, dan lainlain sehingga hal tersebut membuat konsumen lebih tertarik dengan jenis minuman kopi ini. Menu kopi espresso yang disukai di Jigana Coffee Shop diantaranya es koguren, es kopi teh hejo, dan mariana trenche.

Berbeda dengan responden Kedai Kopi Inspirasi yang lebih menyukai jenis minuman kopi manual brew karena sangrai-an serta penyajian dengan alatalat manual yang berbeda ini membuat ciri khas bagi rasa kopi itu sendiri. Ditambah lagi dengan jenis biji single origin yang beragam yang juga membuat konsumen menyukainya. Menu kopi manual brew yang banyak disukai dan diminati oleh konsumen di Kedai Kopi Inspirasi ini adalah Vietnam Drip dan V60.

Hanya sebagian kecil responden yang memilih jawaban tidak tahu. Menurut dari hasil survey di lapangan, hal ini dikarenakan mereka baru saja mencoba kopi di kedai kopi tersebut, sehingga mereka cenderung belum dapat memutuskan serta menentukan menu kopi apa yang mereka sukai. Sebaran responden berdasarkan menu kopi yang paling disukai di Jigana Coffee Shop dan Kedai Kopi Inspirasi tersaji pada Tabel 10.

Tabel 10. Menu Kopi Paling Disukai di Kedai Kopi

\begin{tabular}{lcccc}
\hline $\begin{array}{c}\text { Menu Kopi } \\
\text { Paling } \\
\text { Disukai }\end{array}$ & \multicolumn{2}{c}{$\begin{array}{c}\text { Jigana Coffee } \\
\text { Shop }\end{array}$} & \multicolumn{2}{c}{$\begin{array}{c}\text { Kedai Kopi } \\
\text { Inspirasi }\end{array}$} \\
\cline { 2 - 5 } & $\mathrm{n}$ & $\%$ & $\mathrm{n}$ & $\%$ \\
\hline $\begin{array}{l}\text { Espresso } \\
\text { based }\end{array}$ & 11 & 41 & 15 & 33 \\
$-\begin{array}{l}\text { Manual } \\
\text { Brew }\end{array}$ & 10 & 37 & 24 & 54 \\
- Tidak tahu & 6 & 22 & 6 & 13 \\
\hline$\quad$ Jumlah & 27 & 100 & 45 & 100 \\
\hline Sumber: Analisis data primer (2020)
\end{tabular}

Variabel selanjutnya yang diteliti adalah makanan pelengkap yang paling konsumen sukai. Hal tersebut dikarenakan konsumen juga biasanya memesan makanan pelengkap untuk menemani mereka pada saat menikmati kopi di kedai kopi. Mayoritas dari responden di Jigana Coffee Shop menyukai menu roti bakar. Menu pelengkap selanjutnya yang disukai adalah indomie, kentang goreng, pisang bakar dan lainnya seperti spring roll. Pada Kedai Kopi Inspirasi, mayoritas responden di kedai kopi tersebut menyukai menu pelengkap kentang goreng. Konsumen Jigana Coffee Shop dan Kedai Kopi Inspirasi memilih makanan yang paling mereka sukai tersebut dengan beberapa pertimbangan, seperti harga yang murah serta porsi yang 
banyak sekaligus mengenyangkan.

Sebaran responden berdasarkan menu makanan pelengkap paling disukai di Jigana Coffee Shop dan Kedai Kopi Inspirasi tersaji pada Tabel 11.

Tabel 11. Makanan Pelengkap Paling Disukai di Kedai Kopi

\begin{tabular}{lcccc}
\hline $\begin{array}{c}\text { Makanan } \\
\text { Pelengkap } \\
\text { Paling }\end{array}$ & \multicolumn{2}{c}{$\begin{array}{c}\text { Jigana Coffee } \\
\text { Shop }\end{array}$} & \multicolumn{2}{c}{$\begin{array}{c}\text { Kedai Kopi } \\
\text { Inspirasi }\end{array}$} \\
\cline { 2 - 5 } $\begin{array}{c}\text { Disukai } \\
\text { Dentang }\end{array}$ & $\mathrm{n}$ & $\%$ & $\mathrm{n}$ & $\%$ \\
\hline $\begin{array}{c}\text { Kentang } \\
\text { goreng }\end{array}$ & 4 & 15 & 18 & 40 \\
- Pisang & 2 & 7 & 11 & 25 \\
bakar & 11 & 41 & 6 & 13 \\
- - Roti bakar & 8 & 30 & 8 & 18 \\
- Indomie & 2 & 7 & 2 & 4 \\
- Lainnya & 27 & 100 & 45 & 100 \\
\hline Jumlah & 27 & & & \\
\hline Sumb: An & & & & \\
\hline
\end{tabular}

Sumber: Analisis data primer (2020)

Konsumen Jigana Coffee Shop dan Kedai Kopi Inspirasi juga memiliki menu yang tidak mereka sukai di kedai kopi pilihannya. Menu yang tidak disukai adalah menu kopi dan makanan pelengkap yang pernah mereka coba tetapi tidak cocok dengan selera dan lidah konsumen. Sebaran responden berdasarkan menu yang tidak disukai di Jigana Coffee Shop dan Kedai Kopi Inspirasi tersaji pada Tabel 12 .

Tabel 12. Menu yang Tidak Disukai di Kedai Kopi

\begin{tabular}{ccccc}
\hline $\begin{array}{c}\text { Menu yang } \\
\text { Tidak }\end{array}$ & \multicolumn{2}{c}{$\begin{array}{c}\text { Jigana Coffee } \\
\text { Shop }\end{array}$} & \multicolumn{2}{c}{$\begin{array}{c}\text { Kedai Kopi } \\
\text { Inspirasi }\end{array}$} \\
\cline { 2 - 5 } Disukai & $\mathrm{n}$ & $\%$ & $\mathrm{n}$ & $\%$ \\
\hline - Ada & 1 & 4 & 8 & 18 \\
- Tidak ada & 26 & 96 & 37 & 82 \\
\hline Jumlah & 27 & 100 & 45 & 100 \\
\hline Sumber: Analisis data primer (2020)
\end{tabular}

Berdasarkan Tabel 12, dapat disimpulkan bahwa mayoritas responden Jigana Coffee Shop dan Kedai Kopi Inspirasi memilih untuk tidak ada menu yang tidak mereka sukai. Namun, sebagian responden menyatakan bahwa ada menu yang mereka tidak sukai di kedua kedai kopi tersebut. Hal tersebut dapat dijadikan bahan evaluasi bagi manajemen kedua kedai kopi untuk lebih memperhatikan kembali, terutama Kedai Kopi Inspirasi karena terdapat delapan orang yang pernah mencoba dan tidak cocok dengan selera mereka, seperti espresso based double shot yang kurang mantap rasanya. Alasan lain dari ketidaksukaan sebagian responden terhadap menu yang ada yaitu karena mereka cenderung tidak terlalu menyukai rasa kopi yang terlalu pahit.

\section{Kepuasan Konsumen Setelah}

\section{Berkunjung ke Kedai Kopi}

Setelah konsumen kedua kedai kopi ini melakukan kunjungan ke kedai kopi pilihannya masing-masing, maka konsumen akan membentuk sikap yang juga akan mempengaruhi keinginan mereka untuk berkunjung kembali ke kedai kopi di masa yang akan datang. Sebaran responden berdasarkan penilaian setelah berkunjung ke Jigana Coffee 
Shop dan Kedai Kopi Inspirasi tersaji pada Tabel 13.

Tabel 13. Kepuasan Konsumen Setelah Berkunjung ke Kedai Kopi

\begin{tabular}{|c|c|c|c|c|}
\hline $\begin{array}{l}\text { Kepuasan } \\
\text { Konsumen }\end{array}$ & \multicolumn{2}{|c|}{$\begin{array}{c}\text { Jigana Coffee } \\
\text { Shop } \\
\end{array}$} & \multicolumn{2}{|c|}{$\begin{array}{c}\text { Kedai Kopi } \\
\text { Inspirasi }\end{array}$} \\
\hline $\begin{array}{c}\text { Setelah } \\
\text { Berkunjung }\end{array}$ & $\mathrm{n}$ & $\%$ & $\mathrm{n}$ & $\%$ \\
\hline - Puas & 12 & 44 & 17 & 38 \\
\hline - Cukup puas & 12 & 44 & 25 & 55 \\
\hline - Tidak puas & 3 & 12 & 3 & 7 \\
\hline Jumlah & 27 & 100 & 45 & 100 \\
\hline
\end{tabular}

Sumber: Analisis data primer (2020)

Berdasarkan Tabel 13, kesimpulannya adalah sebagian besar responden dari Jigana Coffee Shop dan Kedai Kopi Inspirasi merasa biasa saja pada saat setelah mereka berkunjung ke kedai kopi pilihannya. Menurut sebagian responden, kedua kedai kopi ini cenderung masih standar dan biasa saja. Selain itu, terdapat juga beberapa responden yang memilih tidak puas.

Pada Jigana Coffee Shop, alasan dari sebagian responden memilih tidak puas setelah berkunjung, yaitu karena rasa kopi yang masih kurang pas, menu yang kurang variatif, suasana masih monoton, dan fasilitas yg belum lengkap. Pada Kedai Kopi Inspirasi, alasan dari sebagian responden memilih tidak puas setelah berkunjung, yaitu karena menurut mereka kedai kopi ini masih tergolong standar, banyak nyamuk di sekitar kedai kopi, pelayanan cenderung lama, penerangan yang kurang, tempatnya cenderung kotor, dan masih ada beberapa menu yang harganya lebih mahal dari kedai kopi lainnya.

\section{Loyalitas Konsumen Setelah \\ Berkunjung ke Kedai Kopi}

Selanjutnya, sebagian besar responden dari Jigana Coffee Shop dan Kedai Kopi Inspirasi menyatakan akan melakukan kunjungan ulang ke kedai kopi pilihannya atau tidak. Jika mereka berminat untuk melakukan kunjungan ulang ke kedai kopi, maka konsumen telah menjadi loyal (Natawidjaja dkk., 2017; Rasmikayati dkk., 2020). Loyalitas konsumen terjadi karena kepuasan yang mereka dapatkan dari aspek tertentu pada saat berkunjung ke kedai kopi. Alasan utama dari sebagian responden yang melakukan kunjungan ulang ke Kedai Kopi Inspirasi yaitu karena suasana yang nyaman. Sebaran responden berdasarkan minat melakukan kunjungan ulang ke Jigana Coffee Shop dan Kedai Kopi Inspirasi tersaji pada Tabel 14.

Tabel 14. Loyalitas Konsumen Berdasarkan Minat Melakukan Kunjungan Ulang ke Kedai Kopi

\begin{tabular}{ccccc}
\hline Minat \\
$\begin{array}{c}\text { Melakukan } \\
\text { Kunjungan }\end{array}$ & \multicolumn{2}{c}{$\begin{array}{c}\text { Jigana Coffee } \\
\text { Shop }\end{array}$} & \multicolumn{2}{c}{$\begin{array}{c}\text { Kedai Kopi } \\
\text { Inspirasi }\end{array}$} \\
\cline { 2 - 5 } Ulang & $\mathrm{n}$ & $\%$ & $\mathrm{n}$ & $\%$ \\
\hline- Ya & 27 & 100 & 43 & 96 \\
- Tidak & - & - & 2 & 4 \\
\hline Jumlah & 27 & 100 & 45 & 100 \\
\hline
\end{tabular}

Sumber: Analisis data primer (2020) 
Berdasarkan Tabel 14, apabila dibandingkan antara Jigana Coffee Shop dan Kedai Kopi Inspirasi, persentase responden yang memilih akan melakukan kunjungan ulang ke Jigana Coffee Shop lebih besar dibandingkan Kedai Kopi Inspirasi. Hal ini dikarenakan terdapat dua orang responden yang menyatakan tidak akan melakukan kunjungan ulang ke Kedai Kopi Inspirasi karena salah satu responden tersebut sudah buka toko satu grup dengan inspirasi, dan satunya lagi merasa kurang nyaman dengan suasana dan harga yang ditawarkan oleh Kedai Kopi Inspirasi.

\section{KESIMPULAN}

Pola pembelian kopi oleh konsumen di Jigana Coffee Shop dan Kedai Kopi Inspirasi kebanyakan dengan alasan sekadar ingin mencoba dan ingin mendapatkan suasana yang nyaman dengan minum kopi di kedai kopi dan bercengkerama bersama teman atau pasangan pada sekitar jam 17.00 hingga 21.00. Adanya potongan harga dan promosi "buy one get one" sangat mempengaruhi minat konsumen untuk berkunjung ke kedai kopi.

Dari segi preferensi konsumen, jenis minuman yang paling disukai adalah Espresso based dan Manual Brew.
Sedangkan untuk jenis minuman yang paling disukai konsumen adalah kentang goreng dan roti bakar. Kemudian mengenai kepuasan dan loyalitas, hasil penelitian menujukkan bahwa sebagian besar konsumen merasa puas setelah melakukan kunjungan ke kedai kopi dan berminat untuk melakukan kunjungan ulang.

\section{DAFTAR PUSTAKA}

Afriyanti, S., \& Rasmikayati, E. (2017). Studi Strategi Pemasaran Terbaik Berdasarkan Perilaku Konsumen dalam Menghadapi Persaingan Antar Kedai Kopi di Jatinangor. Jurnal Manajemen dan Bisnis (Performa), (2), 100-126.

Damanik, Anita Magdalena. (2008). Analisis Sikap dan Preferensi Konsumen terhadap Coffee Shop De Koffie - Pot Bogor. Skirpsi. Jurusan Ilmu-ilmu Sosial Ekonomi Pertanian. Fakultas Pertanian. Institut Pertanian Bogor.

Natawidjaja, R. S., Sulistiowaty, L., Kusno, K., Aryani, D., \& Rachmat, B. (2017). Analisis Preferensi, Kepuasan, dan Kesediaan Konsumen Membayar Beras Di Kota Bandung.

Ramya, N., \& Ali, S. M. (2016). Factors affecting consumer buying behavior. International journal of applied research, 2(10), 76-80.

Rasmikayati, E., Pardian, P., Hapsari, H., Ikhsan, R. M., \& Saefudin, B. R. (2017). Kajian Sikap dan Perilaku Konsumen dalam Pembelian Kopi Serta Pendapatnya Terhadap Varian Produk Dan Potensi Kedainya. Mimbar Agribisnis: Jurnal Pemikiran Masyarakat Ilmiah 
Berwawasan Agribisnis, 3(2), 117133.

DOI:

http://dx.doi.org/10.25157/ma.v3i2. 563.

Rasmikayati, E., Saefudin, B. R., Karyani, T., Kusno, K., \& Rizkiansyah, R. (2020). Analisis Faktor dan Tingkat Kepuasan Ditinjau dari Kualitas Produk dan Pelayanan pada Konsumen Sayuran Organik Di Lotte Mart Kota Bandung. Mimbar Agribisnis: Jurnal Pemikiran Masyarakat Ilmiah Berwawasan Agribisnis, 6(1), 351-364.

Saefudin, B. R., Deanier, A. N., \& Rasmikayati, E. (2020). Kajian Pembandingan Preferensi
Konsumen pada Dua Kedai Kopi di Cibinong, Kabupaten Bogor. AGROVITAL: Jurnal Ilmu Pertanian, 5(1), 39-46. DOI: http://dx.doi.org/10.35329/agrovital .v5i1.637.

Setiadi, Nugroho J. (2013). Perilaku Konsumen. Cetakan 5. Edisi Revisi. Jakarta : Kencana.

Singh, A., \& Verma, P. (2017). Factors influencing Indian consumers' actual buying behaviour towards organic food products. Journal of cleaner production, 167, 473-483.

Sugiyono. (2018). Metode Penelitian Kuantitatif. Bandung: Alfabeta. 